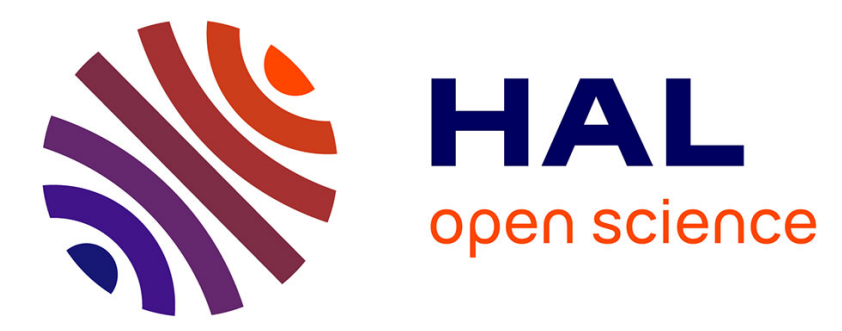

\title{
Weinreb $\beta$-Ketoamides in Enantioselective Organocatalysis: A Balance between Reactivity and Selectivity
}

Haiying Du, Yohan Dudognon, Jean Rodriguez, Thierry Constantieux, Xavier Bugaut

\section{To cite this version:}

Haiying Du, Yohan Dudognon, Jean Rodriguez, Thierry Constantieux, Xavier Bugaut. Weinreb $\beta$-Ketoamides in Enantioselective Organocatalysis: A Balance between Reactivity and Selectivity. SYNLETT, In press, 10.1055/s-0036-1591870 . hal-01723120

\section{HAL Id: hal-01723120 \\ https://hal.science/hal-01723120}

Submitted on 5 Mar 2018

HAL is a multi-disciplinary open access archive for the deposit and dissemination of scientific research documents, whether they are published or not. The documents may come from teaching and research institutions in France or abroad, or from public or private research centers.
L'archive ouverte pluridisciplinaire HAL, est destinée au dépôt et à la diffusion de documents scientifiques de niveau recherche, publiés ou non, émanant des établissements d'enseignement et de recherche français ou étrangers, des laboratoires publics ou privés. 


\section{Weinreb $\beta$-Ketoamides in Enantioselective Organocatalysis: a Balance between Reactivity and Selectivity}

\author{
Haiying Dua \\ Yohan Dudognon \\ Jean Rodriguez $z^{\mathrm{a}}$ \\ Thierry Constantieux \\ Xavier Bugaut*a \\ aix Marseille Univ, CNRS, Centrale Marseille, iSm2, Marseille, \\ France \\ xavier.bugaut@univ-amu.fr
}

\section{Reactivity}

Selectivity

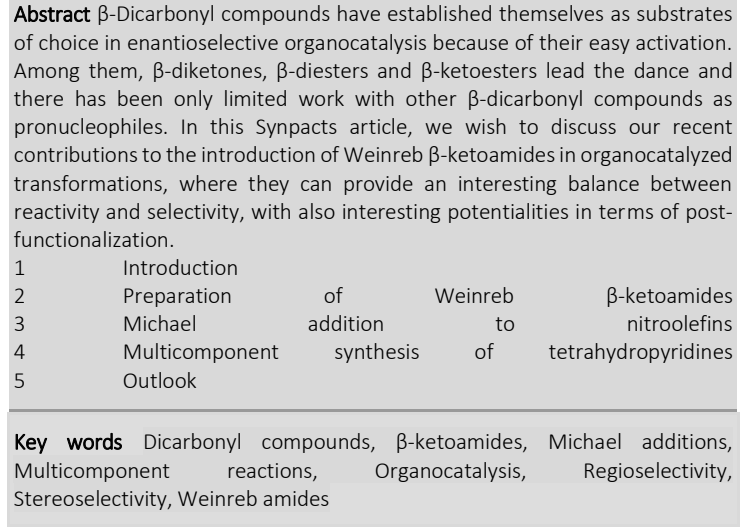

1

The early developments of organocatalysis and its mechanistic recognition are rooted in the origins of organic synthesis, ${ }^{1}$ and it has occasionally been applied to the synthesis of enantioenriched compounds over the $20^{\text {th }}$ century. ${ }^{2}$ However, it is really at the turn of the century that a handful of key reports have created a deep impact on the community of synthetic chemists by the identification of how small chiral non-racemic molecules can catalyze transformations, ${ }^{3}$ paving the way for numerous conceptual and practical developments. ${ }^{4}$ Among the substrates that can be activated by organocatalysts, $\beta$-dicarbonyl compounds are especially interesting pro-nucleophiles. ${ }^{5}$ Indeed, their tautomeric form is easily accessed and can add to a variety of electrophiles, either directly or after deprotonation to the corresponding enolate ion. In those transformations, interactions between the two carbonyl groups and the chiral catalyst can help in the construction of a well-defined transition state, ensuring high enantioselectivities. Even though diversified electrophiles have been used, it is quite surprising that the immense majority of pronucleophiles focused on $\beta$-diketones, $\beta$-diesters and $\beta$ - ketoesters. The main reason for that, is probably their commercial availability and ease of activation thanks to relatively low pKa values (Scheme 1a). ${ }^{6}$ On the contrary, other members of the family such as $\beta$-ketoamides generally need to be prepared and exhibit weaker acidities: for example, in DMSO, a pKa value of 14.2 was determined for ethyl acetoacetate, to be compared with 18.2 for $\mathrm{N}, \mathrm{N}$-dimethylacetoacetamide. ${ }^{7}$ The reduced acidity generally translates in a more difficult activation by basic organocatalysts, but conversely the corresponding anions exhibit higher nucleophilicities (Scheme 1b). ${ }^{8}$ In spite of these difficulties, interesting results have been obtained by us and other research groups for substrates in which the ketone function is included into a ring. ${ }^{9}$ On the opposite, organocatalyzed reactions of linear $\beta$-ketoamides remain very limited.10 As Weinreb amide are generally more acidic than other tertiary amides, we hypothesized that linear Weinreb $\beta$-ketoamides could bring about an interesting alternative for transformations where $\beta$-ketoesters are reactive but not selective enough while the corresponding $\beta$-ketoamides lack reactivity. Moreover, the Weinreb amide functionality in the final product would be amenable to a wide array of post-transformations. ${ }^{11}$

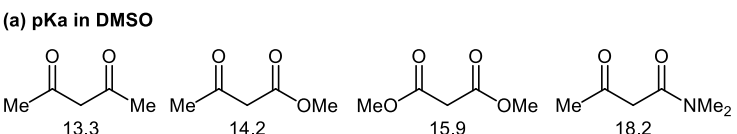
(b) nucleophilicity parameters $\left(N / s_{N}\right)$ in DMSO

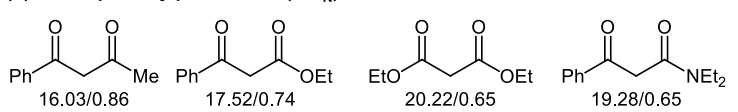

Scheme 1 Physico-chemical parameters of $\beta$-dicarbonyl compounds.

In this Synpacts article, we wish to provide a description of the recent work on the preparation of linear Weinreb $\beta$-ketoamides and their use as original pronucleophiles in enantioselective organocatalysis, where they can allow to reach an interesting equilibrium point between a good reactivity profile and original selectivities. 


\section{Preparation of Weinreb $\beta$-ketoamides}

A prerequisite to develop new transformations on linear Weinreb $\beta$-ketoamides was to be able to prepare diversified substrates. Traditionally, such compounds have been prepared following three main strategies (Scheme 2): (i) the thermal decomposition of diketene (1) or 1,3-dioxin-4-one derivatives $\mathbf{2}$ in the presence of $\mathrm{N}, \mathrm{O}$-dimethylhydroxylamine (3); ${ }^{12}$ (ii) the acylation of $\mathrm{N}$ methoxy- $N$-methylacetamide's enolates $\mathbf{5} ;{ }^{13}$ (iii) the trapping of Mander's type $N$-methoxy- $N$-methylcyanoformamide (7) with lithium enolates $\mathbf{6} .^{14}$

$$
\underset{\substack{\text { (ii) } \\ \text { (iii) }}}{=}
$$

Scheme 2 Different Strategies for the synthesis of $\beta$-ketoamides.

In view of the beneficial effect of microwave heating on Wolff rearrangements for the synthesis of a diversity of $\beta$ ketoamides, ${ }^{15}$ we became interested in applying this method to other reactions of decomposition. Pleasingly, microwave heating of both 2,2,6-trimethyl-1,3-dioxin-4-one (1a) and 5-benzoyl-2,2dimethyl-1,3-dioxane-4,6-dione (10) in the presence of $\mathrm{N}, \mathrm{O}$ dimethylhydroxylamine (3) ${ }^{16}$ afforded the corresponding Weinreb $\beta$-ketoamides $\mathbf{9 a}$ and $\mathbf{9 b}$ in good yields (Scheme 3). ${ }^{17}$

$$
\text { (160" C, 10 min) }
$$

Scheme 3 Synthesis of Weinreb $\beta$-ketoamides under microwave heating.

\section{$3 \quad$ Michael addition to nitroolefins}

Nitroolefins are excellent electrophiles and have established themselves as substrates of choice in enantioselective organocatalysis. ${ }^{18}$ In 2003, the group of Takemoto reported the Michael addition of $\beta$-dicarbonyl compounds to nitroolefins in the presence of a chiral bifunctional thiourea $\mathbf{A}$ bearing a pendant tertiary amine. ${ }^{19}$ Two models have been proposed to explain the activation and the stereoselectivity, involving hydrogen bonding of the thiourea either with the nitroolefin ${ }^{20}$ or with the $\beta$ dicarbonyl compound. ${ }^{21} \mathrm{~A}$ limitation of this transformation is found when linear $\beta$-ketoesters $\mathbf{1 1}$ are used in combination with nitrostyrene (12). Indeed, the corresponding Michael adducts 13 were obtained with good yields and enantioselectivities, but with no diastereoselectivity, damaging the synthetic usefulness of the transformation (Scheme 4a). ${ }^{20}$ Other related studies brought similar observations, ${ }^{22}$ and monitoring of $d r$ over time showed that some catalyst-controlled diastereoselectivity could be achieved during carbon-carbon bond formation. However, rather fast base-catalyzed epimerization annihilated the diastereoselectivity. ${ }^{17,22 \mathrm{~d}}$ There is a single example of reaction with tert-butyl acetoacetate (14) in the presence of polyfunctional squaramide B, with product $\mathbf{1 5}$ reaching 5.3:1 dr (Scheme 4b). ${ }^{23}$ The comparatively good diastereoselectivity could probably be ascribed to the low catalyst loading and the buffering effect of the phenolic groups that probably tame the overall basicity of catalyst $\mathbf{B}$.

(a)
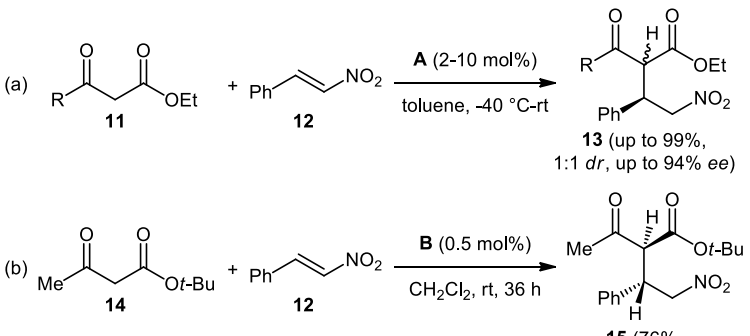
$53: 1$ ( $15 \%$,

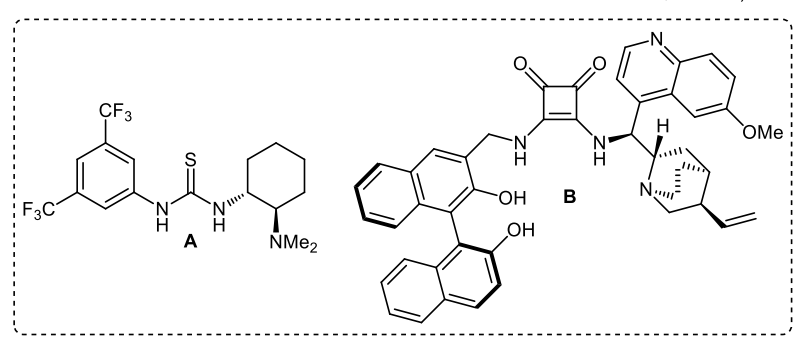

Scheme 4 Thiourea- or squaramide-catalyzed addition of $\beta$ ketoesters to nitrostyrene.

Based on these observations, we hypothesized that the reduced acidity of $\beta$-ketoamides could help preventing epimerization, opening possibilities for a completely stereoselective transformation. To test this hypothesis, diversely substituted $\beta$ ketoamides 9a,16b-d were mixed with nitrostyrene (12) to afford Michael adducts 17a-d (Table 1). ${ }^{17}$ At first, different bifunctional hydrogen-bonding catalysts $\mathbf{A , C}-\mathbf{G}$ were evaluated in the presence of Weinreb $\beta$-ketoamide 9a. Takemoto catalyst $\mathbf{A}$ delivered the expected product 17a but both diastereo- and enantioselectivities were disappointing (Entry 1 ), while quininederived thiourea $\mathbf{C}$ brought only marginal improvement (Entry 2). ${ }^{24}$ We then turned our attention towards squaramide catalysts. ${ }^{22 a, 25}$ Catalyst $\mathbf{D}$ bearing an aromatic substituent on the nitrogen atom of the squaramide moiety performed also poorly (Entry 3), in sharp contrast with those flanked with a benzylic substituent (Entries 4-6). Indeed, the three catalyst E-G delivered the expected product not only with high yields (94-99\%) and enantiomeric excesses $(95-98 \%$ ee $)$, but also excellent diastereomeric ratios (15:1-17:1 $d r$ ). Moreover, reducing the reaction time to $14 \mathrm{~h}$ did not affect these results (Entry 7). Other substrates such as secondary $\beta$-ketoamides 16b-c bearing either a phenyl or a benzyl group were also evaluated. In both cases, diastereoselectivity was very low (Entries 8,9). On the contrary, tertiary $\beta$-ketoamide $\mathbf{1 6 d}$ could also be converted to the corresponding product $\mathbf{1 7 d}$ with an excellent diastereoselectivity but a slightly reduced yield and slower kinetic (Entry 10). More generally, evaluation of the reaction rate 
led to two conclusions: ${ }^{17}$ (i) catalyst $\mathbf{E}$ is not only more selective than $\mathbf{D}$, but also about 10 times faster; (ii) the reaction with $\beta$ ketoesters and secondary $\beta$-ketoamides is very fast, yet not diastereoselective, and the one with tertiary $\beta$-ketoamides much slower, while Weinreb $\beta$-ketoamide 9a allows to find the best balance between reactivity and stereoselectivities.

Table 1 Evaluation of various $\beta$-ketoamides in the organocatalyzed Michael addition to nitroolefins. ${ }^{17}$

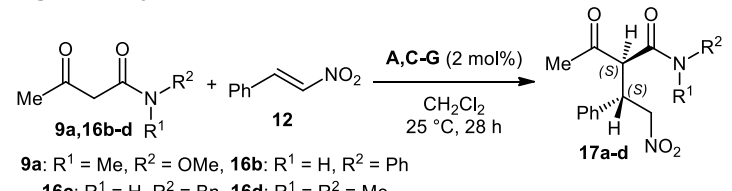

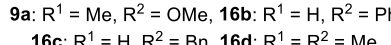

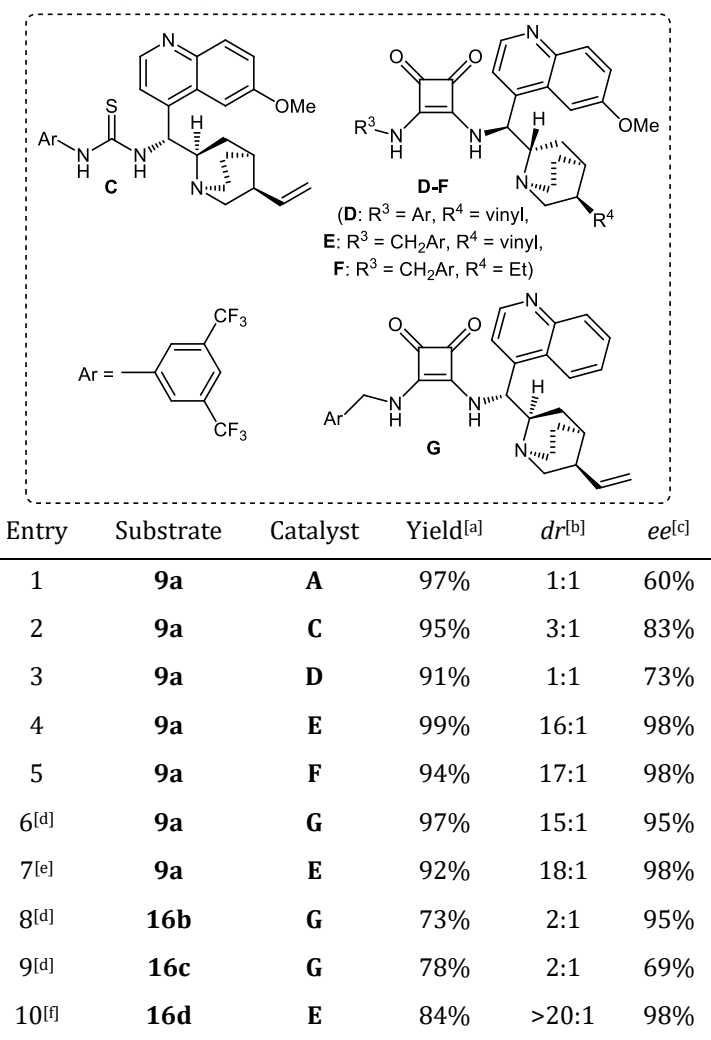

[a] Yield of product isolated by flash chromatography. [b] Determined by ${ }^{1} \mathrm{H}$ NMR spectroscopy of the crude reaction mixture. [c] Value for the major diastereomer determined by HPLC on chiral stationary phase. [d] The other enantiomer of the product was obtained. [e] Reaction time: $14 \mathrm{~h}$. [f] Reaction time: $35 \mathrm{~h}$.

With the optimized reaction conditions in hand, Weinreb $\beta$ ketoamide 9a was evaluated in the presence of various nitroolefins 18a-g (Table 2). Irrespective of the electronic nature or positions of their substituents, all nitroolefins bearing a (hetero)aromatic group in $\beta$-position furnished the expected products 19a-e in good yields and with excellent stereoselectivities. Both the absolute and relative configurations of product 19c could be secured by analysis by X-ray diffraction, and the configurations of the other products were attributed by analogy. In addition to this, aliphatic nitroolefin $\mathbf{1 8 f}$ and the trisubstituted one $\mathbf{1 8 g}$ reacted with decent stereocontrol, the presence of diastereomers in $19 \mathrm{~g}$ being explained by an additional epimerizable stereocenter in $\alpha$-position to the nitro group. ${ }^{26}$

Table 2 Scope of nitroolefins in the organocatalyzed Michael addition of $\beta$-ketoamide $\mathbf{9 a}$. $^{17}$

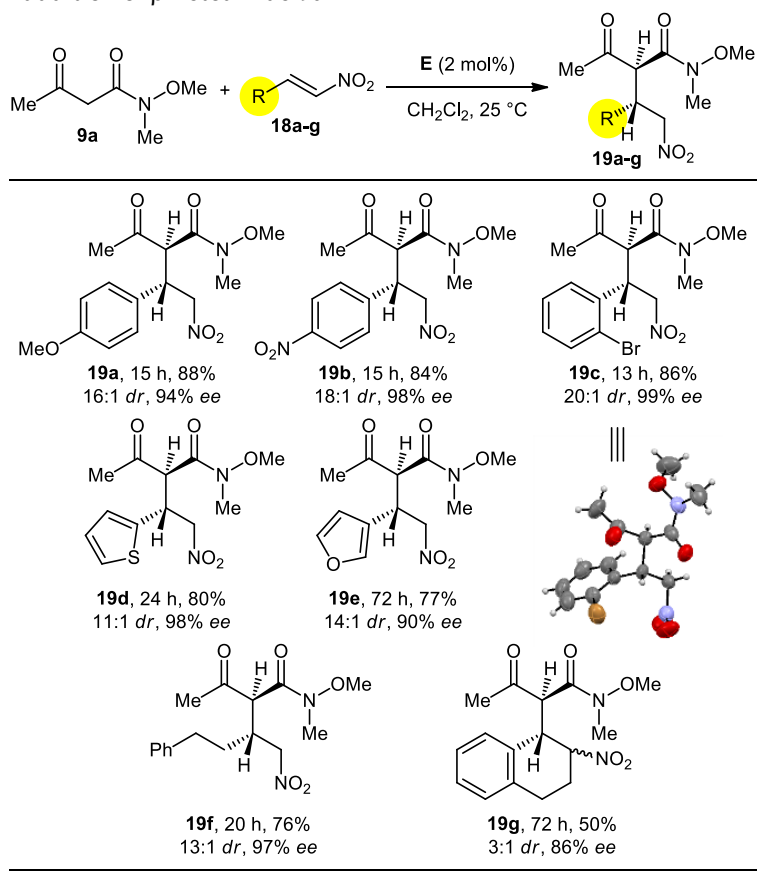

Yield of product isolated by flash chromatography. $d r$ determined by ${ }^{1} \mathrm{H}$ NMR spectroscopy of the crude reaction mixture. $e e$ value for the major diastereomer determined by HPLC on chiral stationary phase.

Table 3 Scope of Weinreb $\beta$-ketoamides in the organocatalyzed Michael addition to nitrostyrene (13). ${ }^{17}$

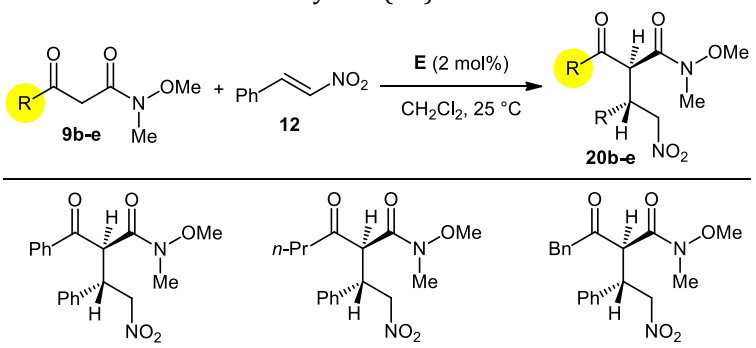

20b, $14 \mathrm{~h}, 74 \%$

$3: 1 d r, 92 \%$ ee

$20 \mathrm{c}, 14 \mathrm{~h}, 81 \%$
$12: 1 \mathrm{dr}, 99 \%$ ee

20d, $14 \mathrm{~h}, 76 \%$

-

20e, $26 \mathrm{~h}, 72 \%$

$8: 1 d r, 96 \%$ ee

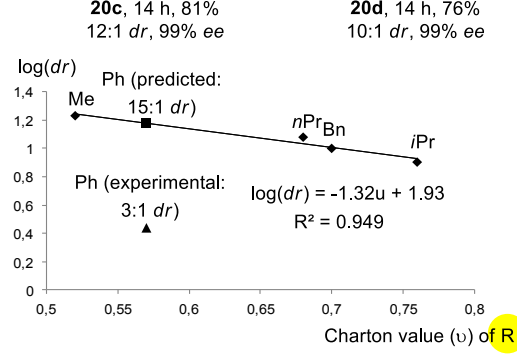

Yield of product isolated by flash chromatography. $d r$ determined by ${ }^{1} \mathrm{H}$ NMR spectroscopy of the crude reaction mixture. ee value for the major diastereomer determined by HPLC on chiral stationary phase. 
Conversely, nitrostyrene (12) was reacted with a series of Weinreb $\beta$-ketoamides $\mathbf{9 b}$-e to deliver the Michael adducts 20b$\mathbf{e}$ in good yields and with excellent enantiomeric excesses (Table 3 ). However, we could notice that the diastereomeric ratio decreased with the bulkiness of the substituent on the ketone side. For products 20a,c-e bearing aliphatic substituents, a linear free-energy relationship (LFER) between $\log (d r)$ and the Charton steric parameter of the $\mathrm{R}$ was identified..$^{27}$ This observation, together with control experiments showed that the reaction is not reversible and no epimerization of the product can occur in the reaction conditions, ${ }^{17}$ pointing towards a steric-dependent kinetic diastereocontrol, enabled by catalyst $\mathbf{E}$. On the opposite, product 20b containing an aromatic ketone does not follow the LFER showing that epimerization is not completely suppressed in that case.

Concomitantly with our studies, the group of Nagasawa reported a single example of the same reaction with $\beta$-ketoamide $9 \mathbf{a}$ and nitrostyrene (12) in the presence of a guanidinium-bis-thiourea organocatalyst I and DABCO (Scheme 5). ${ }^{28}$ In a similar fashion to our work, product ent-17a was obtained with a very high degree of control of both the diastereo- and the enantioselectivities, whereas the corresponding reaction with linear $\beta$-ketoesters was not diastereoselective.

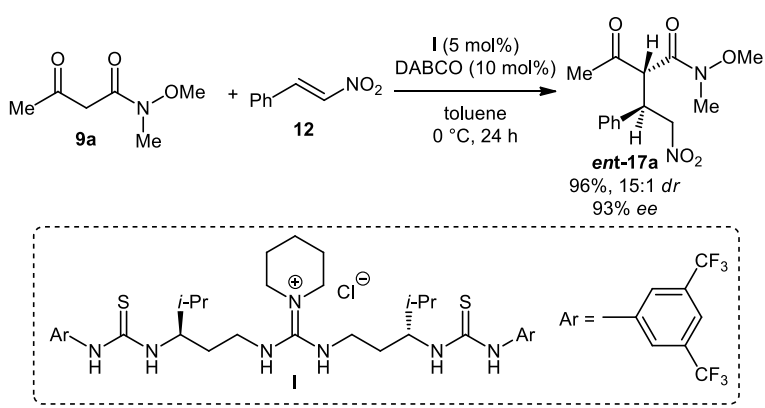

Scheme 5 A related report by the group of Nagasawa.

Having shown that the replacement of $\beta$-ketoesters by Weinreb $\beta$-ketoamides was advantageous in their Michael additions to nitroolefins in terms of diastereoselectivity, we then wanted to exploit their synthetic potential (Scheme 6). At first, scale-up to half-gram scale proceeded uneventfully and offered the possibility to carry out the reaction in neat conditions and to decrease both the catalyst loading to $0.5 \mathrm{~mol} \%$ and the reaction time to 3 hours. In terms of post-functionalization, the diastereoselective reduction of the ketone function of $\mathbf{1 7 a d}$ into the corresponding alcohols $\mathbf{2 1}$ would deliver highly functionalized stereotriads. Pleasingly, $\mathrm{NaBH}_{4}$ in the presence of a Lewis acid enabled a syn reduction with a high level of diastereocontrol $(13: 1 \quad d r) .{ }^{29}$ Anti reduction was more challenging but could finally be achieved with moderate diastereoselectivity $(7: 1 d r)$ by using $\mathrm{Me}_{4} \mathrm{NBH}_{4}$ as a bulky hydride donor at low temperature. ${ }^{30}$ Weinreb amides have become popular substrates in organic synthesis because of their tendency to undergo selectively mono-additions of hydrides or organometallic reagents, contrary to other carboxylic acid derivatives such as esters. ${ }^{11}$ Treatment of syn-21 with $\mathrm{LiAlH}_{4}$ actually reduced the amide function into the corresponding aldehyde, but was also accompanied by dehydration. Although this transformation destroys two stereocenters, it is still synthetically interesting as enal $\mathbf{2 2}$ could be seen as the product of a formal Rauhut-Currier reaction between crotonaldehyde and nitrostyrene, a reaction for which no enantioselective variant existed at that time. ${ }^{31}$ Protection of the alcohol function as a silyl ether followed by the reduction of $\mathbf{2 3}$ delivered $\beta$ hydroxyaldehyde $\mathbf{2 4}$ with a moderate yield. We currently work on the application of the overall synthetic sequence to the synthesis of natural products.
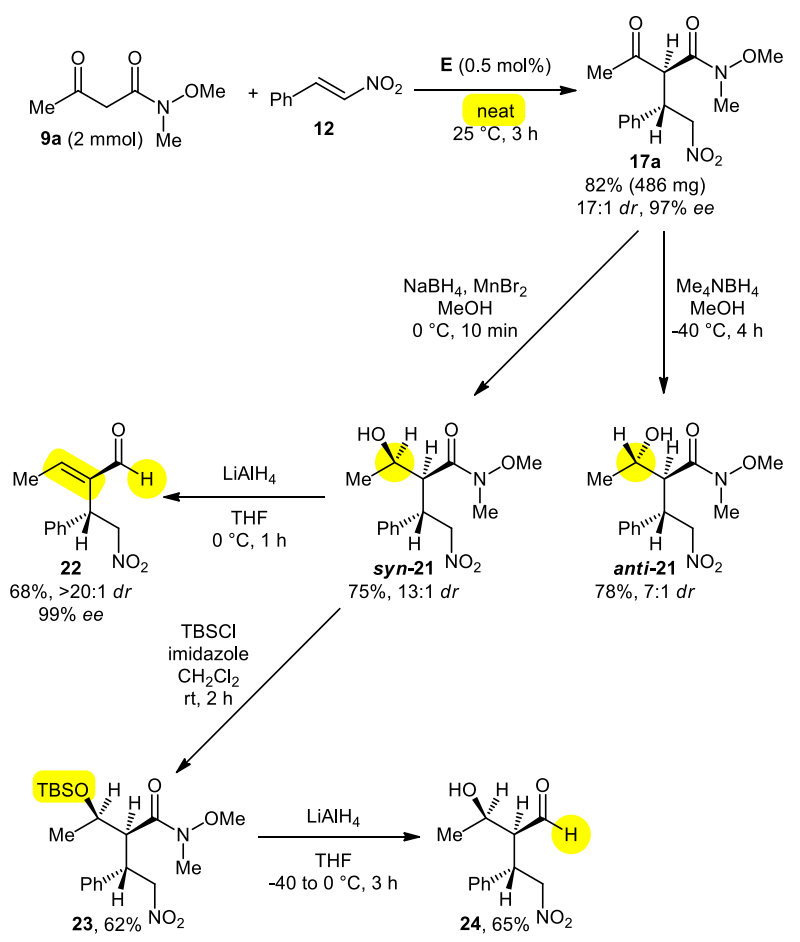

Scheme 6 Scale-up and post-functionalization of Michael adducts. ${ }^{17}$

\section{$4 \quad$ Multicomponent synthesis of tetrahydropyridines}

With this first successful application of Weinreb $\beta$-ketoamides in organocatalysis, we wondered whether they could also replace advantageously the corresponding $\beta$-ketoesters in other transformations.

Multicomponent reactions (MCRs) consist in a transformation where three or more reaction partners are assembled to form a single product that retains most atoms of the starting materials. ${ }^{32}$ They represent extremely powerful tools for the synthesis of polyheterocyclic structures..$^{33}$ MCRs generally rely on the use of polyfunctional substrates bearing at the same time electrophilic and nucleophilic positions allowing to link the other reaction partners. For this reason, $\beta$-dicarbonyl compounds are especially appealing candidates for MCRs, ${ }^{34}$ and organocatalysis an efficient tool to control their enantioselectivities. ${ }^{35} \mathrm{~A}$ typical strategy is to combine a $\beta$-dicarbonyl compound, an $\alpha, \beta$-unsaturated carbonyl compound and an amine bearing a pendant nucleophile to obtain 1,4,5,6-tetrahydropyridines 25 (Scheme 7a). ${ }^{36}$ We became intrigued in the possibility to reverse the regioselectivity of the final cyclization from intermediate 1,4-dihydropyridines $\mathbf{2 6}$ to prepare regioisomeric 1,2,3,4-tetrahydropyridines 27. (Scheme 7b). ${ }^{37} \mathrm{~A}$ careful analysis of the structures of $\mathbf{2 5}$ and $\mathbf{2 7}$ reveal that the former one is likely to be more stable since its enamine 
moiety is conjugated with the carbonyl compound, which is not the case for 27. Disfavoring the conjugation should then help to drive the reaction towards the formation of 27 . Our working hypothesis was that this could be achieved by using a $\beta$ ketoamide, whose increased pKa value and steric demand would both play against conjugation (Scheme 7c).

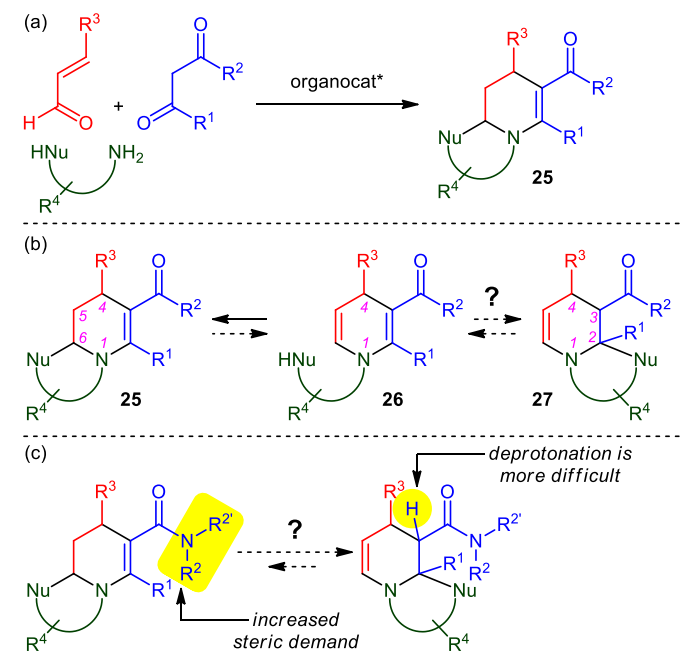

Scheme 7 Synthesis of tetrahydropyridines via organocatalyzed enantioselective MCRs
To test our hypothesis, we embarked on the evaluation of several $\beta$-dicarbonyl compounds (9a, 16d and 29a,b) and bisnucleophiles 30a,b in combination with cinnamaldehyde (28a) and Hayashi-Jørgensen catalyst $\mathbf{J}$ (Table 4). ${ }^{38}$ The catalyst controls the enantioselectivity of the initial Michael addition by the formation of a transient chiral iminium ion. The potential formation of regioisomeric products 25a-e and 27a-e was evaluated, along with their diastereomeric ratios and enantiomeric excesses. Starting with tert-butyl acetoacetate (29a) and 2-aminobenzyl alcohol (30a) in $\mathrm{C}_{6} \mathrm{H}_{5} \mathrm{CF}_{3}$ at $0{ }^{\circ} \mathrm{C}$ for 48 $\mathrm{h}$, only the 1,4,5,6-tetrahydropyridine $\mathbf{2 5 a}$ was obtained as a mixture of diastereomers and with acceptable enantioselectivity (Entry 1). Using 2-aminophenol (30b) as the bis-nucleophile delivered the two regioisomers $\mathbf{2 5 b}$ and 27b (Entry 2). Pleasingly, the latter product was isolated as a single diastereomer and with $94 \%$ ee. Switching to Weinreb $\beta$ ketoamide 9 a opened the possibility for a complete regiocontrol (Entry 3): indeed, only the 1,2,3,4-tetrahydropyridine $\mathbf{2 7} \mathbf{c}$ was observed, once again without any contamination from other diastereomers. ${ }^{40} \mathrm{~A}$ thorough optimization study was initiated to improve the yield of product. ${ }^{39}$ Using $\mathrm{CH}_{2} \mathrm{Cl}_{2}$ as the solvent improved it slightly (28\% yield) and allowed to verify that the reaction was highly enantioselective $(93 \%$ ee, Entry 4). Adding $\mathrm{BzOH}$ as a co-catalyst allowed to reach a similar yield with a halved reaction time (Entry 5). Increasing the reaction temperature to $10^{\circ} \mathrm{C}$ and doubling the catalysts' loadings allowed to isolate $27 \mathrm{c}$ in $60 \%$ yield, with $>20: 1 d r$ and $94 \% e e$ (Entry 6).

Table 4 Evaluation of various $\beta$-dicarbonyl compounds and bis-nucleophiles for the synthesis of enantioenriched 1,2,3,4tetrahydropyridines through an organocatalyzed MCR. ${ }^{39}$<smiles>O=CC=Cc1ccccc1</smiles><smiles>[X]C(=O)CC([Y])=O</smiles>

9a: $X=\mathrm{N}(\mathrm{Me}) \mathrm{OMe}$

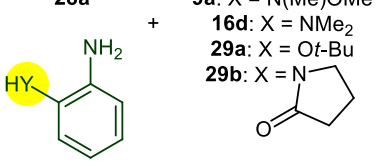

30a: $\mathrm{Y}=\mathrm{CH}_{2} \mathrm{O}$

30b: $Y=O$

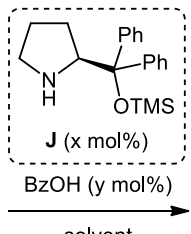
temperature, time
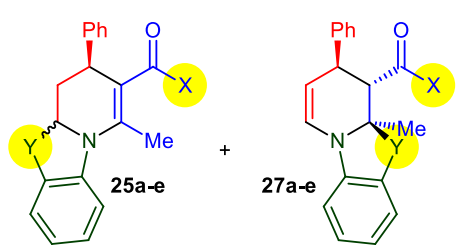

\begin{tabular}{|c|c|c|c|c|c|c|c|}
\hline Entry & Substrates & $\mathrm{x}$ & $\mathrm{y}$ & Solvent & Temperature $\left({ }^{\circ} \mathrm{C}\right)$ & Time (h) & Products (Yield[a], $\left.d r^{[\mathrm{b}]}, e e^{[\mathrm{c}]}\right)$ \\
\hline 1 & $29 a, 30 a$ & 10 & 0 & $\mathrm{C}_{6} \mathrm{H}_{5} \mathrm{CF}_{3}$ & 0 & 48 & Only $\mathbf{2 5 a}(27 \%, 1.3: 1,88 \%)$ \\
\hline 2 & $29 a, 30 b$ & 10 & 0 & $\mathrm{C}_{6} \mathrm{H}_{5} \mathrm{CF}_{3}$ & 0 & 48 & $\begin{array}{c}25 \mathbf{b}\left(12 \%, 1.5: 1, \mathrm{nd}^{[\mathrm{d}]}\right) \text { and } \\
\mathbf{2 7 b}(25 \%,>20: 1,94 \%)\end{array}$ \\
\hline 3 & $9 a, 30 b$ & 10 & 0 & $\mathrm{C}_{6} \mathrm{H}_{5} \mathrm{CF}_{3}$ & 0 & 48 & Only 27c $\left(19 \%,>20: 1, \mathrm{nd}^{[\mathrm{d}]}\right)$ \\
\hline 4 & $9 a, 30 b$ & 10 & 0 & $\mathrm{CH}_{2} \mathrm{Cl}_{2}$ & 0 & 48 & Only 27 c $(28 \%,>20: 1,93 \%)$ \\
\hline 5 & $9 a, 30 b$ & 10 & 20 & $\mathrm{CH}_{2} \mathrm{Cl}_{2}$ & 0 & 24 & Only 27c (32\%, >20:1, 95\%) \\
\hline 6 & $9 a, 30 b$ & 20 & 40 & $\mathrm{CH}_{2} \mathrm{Cl}_{2}$ & 10 & 60 & Only 27 c $(60 \%,>20: 1,94 \%)$ \\
\hline 7 & $9 a, 30 b^{[e]}$ & 20 & 40 & $\mathrm{CH}_{2} \mathrm{Cl}_{2}$ & 10 & 60 & Only $27 \mathrm{c}(50 \%,>20: 1,72 \%)$ \\
\hline 8 & $16 \mathrm{~d}, 30 \mathrm{~b}$ & 20 & 40 & $\mathrm{CH}_{2} \mathrm{Cl}_{2}$ & 10 & 60 & Only $27 d$ (29\%, >20:1, 92\%) \\
\hline 9 & $29 b, 30 b$ & 20 & 40 & $\mathrm{CH}_{2} \mathrm{Cl}_{2}$ & 10 & 60 & $\begin{array}{l}\text { Complex mixture containing } \\
25 \mathbf{e} \text { and } 27 \mathbf{e}\end{array}$ \\
\hline
\end{tabular}

[a] Yield of product isolated by flash chromatography. [b] Determined by ${ }^{1} \mathrm{H}$ NMR spectroscopy of the crude reaction mixture. [c] Value for the major diastereomer determined by HPLC on chiral stationary phase. [d] Not determined. [e] Sequential reaction conditions: 2aminophenol was added after $48 \mathrm{~h}$ of reaction. 
Assuming that the loss of yield could be attributed to the formation of unproductive imine and enamine derivatives, we tried to perform at first the enantioselective Michael addition and to add 2-aminophenol (30b) later (Entry 7). Not only the yield was not improved but there was also a strong decrease of the enantiomeric excess. This result highlights an interesting feature of domino and multicomponent reactions, in which potentially sensitive reaction intermediates can be transformed to more stable products before racemization and/or degradation. Tertiary $\beta$-ketoamide 16d also afforded 1,2,3,4tetrahydropyridine $\mathbf{2 7 d}$ with excellent regio- and stereoselectivities but in only 29\% yield (Entry 8), while pyrrolidinone-derived $\beta$-ketoamide $29 \mathrm{~b}$ resulted in a nonregioselective and sluggish reaction (Entry 9). All these observations once again indicate that Weinreb $\beta$-ketoamides present an interesting profile to reach a compromise between reactivity and selectivity.

With these optimized reaction conditions in hands, Weinreb $\beta$ ketoamide 9a was placed in the presence of substituted enals 28b-f and 2-aminophenols 30b-g to deliver products 27bb-eg in moderate yields as only one regio- and stereoisomer, with enantiomeric excesses ranging from $82 \%$ to $96 \%$ (Table 5). Both the yields and enantiomeric excesses tended to increase when more electron-deficient enals where used (Entries 1-5). On the opposite, the electronic nature of the substituent on the 2aminophenol had only a limited influence on the reaction outcome (Entries 6-9), with 3-aminonaphth-2-ol (30g) giving the best ee (Entry 10).

Table 5 Scope of substituted enals and 2-aminophenols in the organocatalyzed synthesis of 1,2,3,4-tetrahydropyridines. ${ }^{39}$

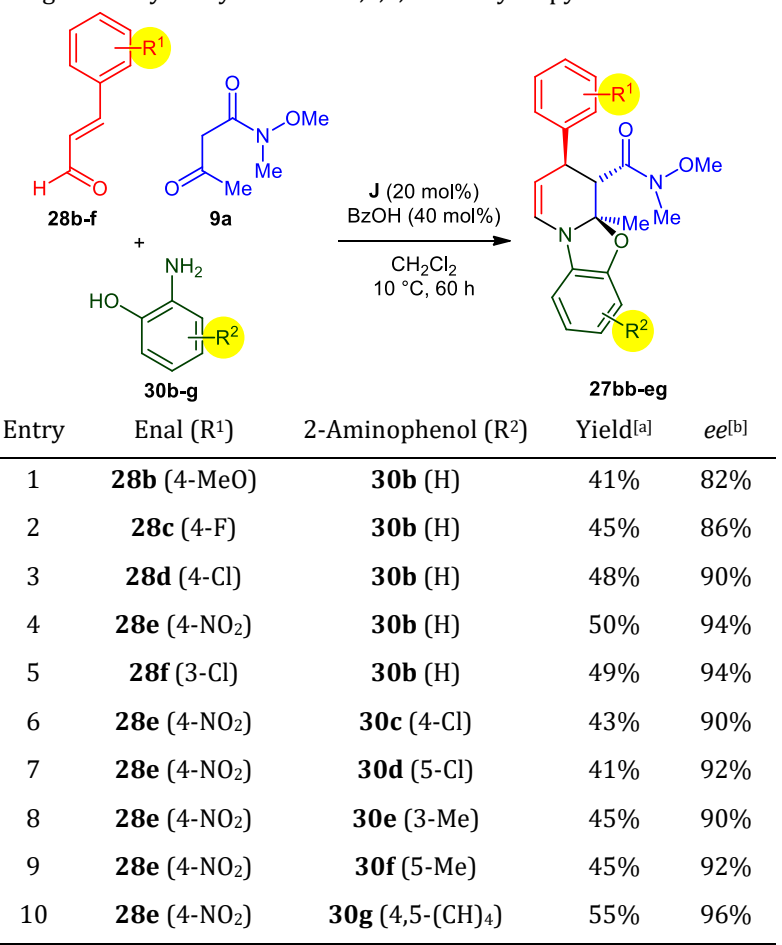

[a] Yield of product isolated by flash chromatography. For all products, $d r$ determined by ${ }^{1} \mathrm{H}$ NMR spectroscopy of the crude reaction mixture was $>20: 1$. [b] Value for the major diastereomer determined by HPLC on chiral stationary phase.
An interesting feature of 1,2,3,4-tetrahydropyridines of type 27 is that they bear a potentially reactive enamine function (Scheme 8). In the presence of a Lewis acid such as $\mathrm{Sc}(\mathrm{OTf})_{3}$, the resulting iminium ion could be trapped by a nucleophile. For example, the combination of 27eg with potassium phenylethynyltrifluoroborate (31) delivered highly substituted piperidine $\mathbf{3 2}$ in good yield, as a single diastereomer and with only a minor erosion of the enantiomeric excess (from $94 \%$ to $90 \%){ }^{40,41}$ Catalytic hydrogenation of the enamine is also straightforward as illustrated with the formation of piperidine 33 in good yield from 27c. It is then possible to reveal the reactivity of the $\mathrm{N}, \mathrm{O}$-acetal that can open to the corresponding iminium ion, also in the presence of $\mathrm{Sc}(\mathrm{OTf})_{3}$. Once again using 31 as the nucleophile resulted in the diastereoselective formation of 34 in moderate yield. The enamine function can also participate as an electron-rich $2 \pi$-partner in an inverse-demand heteroDiels-Alder reaction: the Povarov reaction with the imine formed in-situ from ethyl glyoxylate (35) and $p$-anisidine (36) afforded the polycyclic structure $\mathbf{3 7}$ without any racemization. ${ }^{42}$ The two new stereogenic centers on the central piperidine ring are fully controlled, but not the one $\alpha$ to the ester function, resulting in the existence of two diastereomers. ${ }^{40}$

Scheme 8 Post-functionalization of 1,2,3,4tetrahydropyridines. ${ }^{39}$
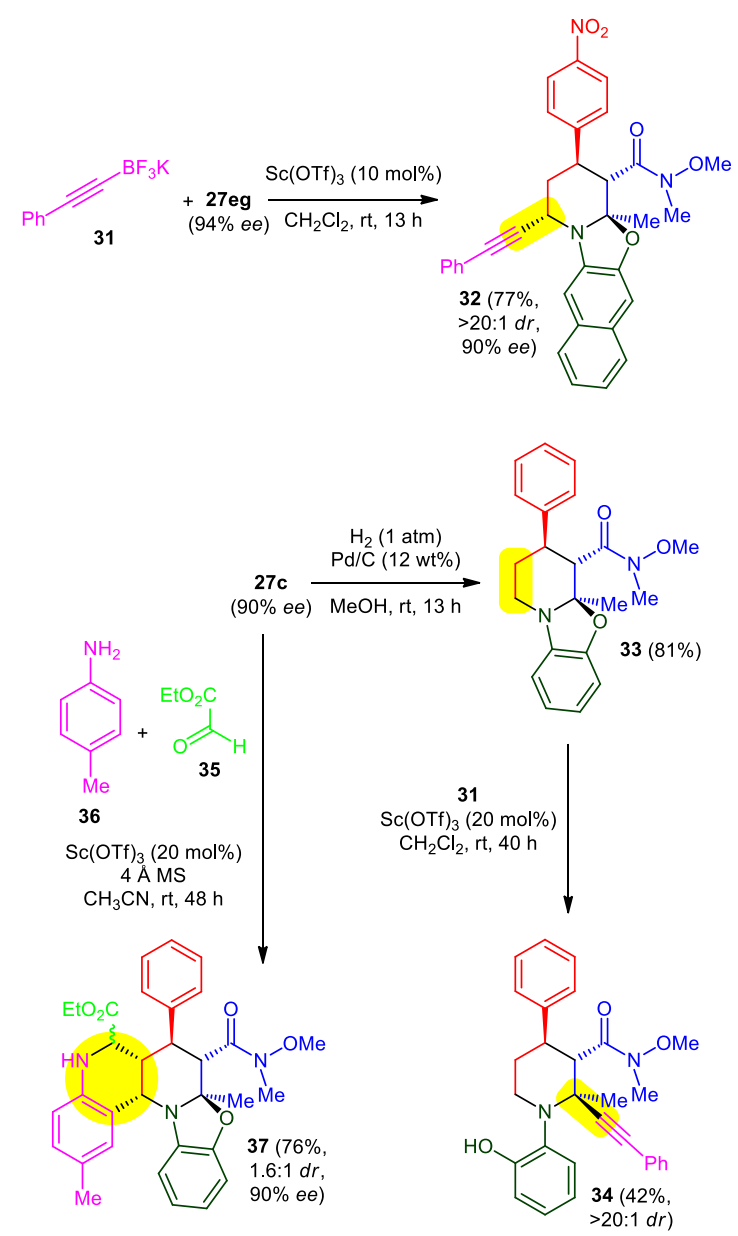


\section{Outlook}

In this Synpacts article, we wished to highlight how the specific electronic and steric properties of linear Weinreb $\beta$-ketoamides can influence their behavior in organocatalyzed enantioselective transformations. They occupy a special position halfway between $\beta$-ketoesters and other $\beta$-ketoamides, which allow to find a fine balance between reactivity and selectivity. Their unique features could be exemplified by the control of diastereoselectivity in their Michael addition to nitroolefins in the presence of a bifunctional hydrogen-bonding catalyst, ${ }^{17}$ and the reversal of regioselectivity in the preparation of tetrahydropyridines through a MCR with iminium activation. ${ }^{39}$ We strongly believe that their systematic evaluation in organocatalyzed transformations involving $\beta$ dicarbonyl compounds as substrates will result in other important findings in the near future.

\section{Funding Information}

Financial support from Aix Marseille Université, Centrale Marseille and the CNRS, along with scholarships from the China Scholarship Council (H.Y.D.) and the Ministère de l'Enseignement Supérieur et de la Recherche (Y.D.) are acknowledged.

\section{Acknowledgment}

We warmly thank Dr. Nicolas Vanthuyne and Marion Jean for HPLC analyses on chiral stationary phase, and the whole team of the Spectropole (www.spectropole.fr) for NMR and MS analyses.

\section{References}

(1) (a) von Liebig, J. Justus Liebigs Ann. Chem. 1860, 113, 246. (b) Langenbeck, W. Justus Liebigs Ann. Chem. 1929, 469, 16.

(2) Selected examples: (a) Bredig, G.; Fiske, P. S. Biochem. Z. 1912, 46, 7. (b) Pracejus, H. Justus Liebigs Ann. Chem. 1960, 634, 9. (c) Eder, U.; Sauer, G.; Wiechert, R. Angew. Chem., Int. Ed. Engl. 1971, 10, 496. (d) Sheehan, J. C.; Hara, T. J. Org. Chem. 1974, 39, 1196. (e) Hajos, Z. G.; Parrish, D. R. J. Org. Chem. 1974, 39, 1615. (f) Tu, Y.; Wang, Z.X.; Shi, Y. J. Am. Chem. Soc. 1996, 118, 9806.

(3) (a) Sigman, M. S.; Jacobsen, E. N. J. Am. Chem. Soc. 1998, 120, 4901. (b) Ahrendt, K. A.; Borths, C. J.; MacMillan, D. W. C. J. Am. Chem. Soc. 2000, 122, 4243. (c) List, B. J. Am. Chem. Soc. 2000, 122, 9336.

(4) (a) "Asymmetric Organocatalysis", in Science of Synthesis, List, B. and Maruoka, K., Eds; Georg Thieme Verlag KG: Stuttgart; 2012. (b) "Comprehensive Enantioselective Organocatalysis", Dalko, P., Ed.; Wiley-VCH: Weinheim; 2013.

(5) (a) Bonne, D.; Constantieux, T.; Coquerel, Y.; Rodriguez, J. Chem. Eur. J. 2013, 19, 2218. (b) Govender, T.; Arvidsson, P. I.; Maguire, G. E. M.; Kruger, H. G.; Naicker, T. Chem. Rev. 2016, 116, 9375.

(6) (a) Olmstead, W. N.; Bordwell, F. G. J. Org. Chem. 1980, 45, 3299. (b) Bordwell, F. G.; Harrelson Jr, J. A. Can. J. Chem. 1990, 68, 1714. (c) Arnett, E. M.; Maroldo, S. G.; Schilling, S. L.; Harrelson, J. A. J. Am. Chem. Soc. 1984, 106, 6759.

(7) Bordwell, F. G.; Fried, H. E. J. Org. Chem. 1991, 56, 4218

(8) Corral-Bautista, F.; Appel, R.; Frickel, J. S.; Mayr, H. Chem. Eur. J. 2015, 21, 875.

(9) For selected examples, see: (a) Elsner, P.; Jiang, H.; Nielsen, J. B.; Pasi, F.; Jorgensen, K. A. Chem. Commun. 2008, 5827. (b) Pan, Y.; Zhao, Y.; Ma, T.; Yang, Y.; Liu, H.; Jiang, Z.; Tan, C.-H. Chem. Eur. J. 2010, 16, 779. (c) Sanchez Duque, M. M.; Baslé, O.; Isambert, N.; Gaudel-Siri, A.; Génisson, Y.; Plaquevent, J.-C.; Rodriguez, J.; Constantieux, T. Org. Lett. 2011, 13, 3296. (d) Mailhol, D.; Sanchez Duque, M. d. M.; Raimondi, W.; Bonne, D.; Constantieux, T.; Coquerel, Y.; Rodriguez, J. Adv. Synth. Catal. 2012, 354, 3523. (e) De Fusco, C.; Meninno, S.; Tedesco, C.; Lattanzi, A. Org. Biomol. Chem. 2013, 11, 896. (f) Mailhol, D.; Castillo, J.-C.; Mohanan, K.; Abonia, R.; Coquerel, Y.; Rodriguez, J. ChemCatChem 2013, 5, 1192. (g) Sanchez Duque, M. M.; Baslé, O.: Génisson, Y.: Plaquevent, I.-C.:
Bugaut, X.; Constantieux, T.; Rodriguez, J. Angew. Chem. Int. Ed. 2013, 52, 14143. (h) Goudedranche, S.; Bugaut, X.; Constantieux, T.; Bonne, D.; Rodriguez, J. Chem. Eur. J. 2014, 20, 410. (i) Zhu, Y.; Zhang, L.; Luo, S. J. Am. Chem. Soc. 2014, 136, 14642. (j) Quintard, A.; Cheshmedzhieva, D.; Sanchez Duque, M. M.; Gaudel-Siri, A.; Naubron, J.-V.; Génisson, Y.; Plaquevent, J.-C.; Bugaut, X.; Rodriguez, J.; Constantieux, T. Chem. Eur. J. 2015, 21, 778.

(10) For selected examples, see: (a) Bertelsen, S.; Johansen, R. L.; Jorgensen, K. A. Chem. Commun. 2008, 3016. (b) Hatano, M.; Horibe, T.; Ishihara, K. J. Am. Chem. Soc. 2009, 132, 56. (c) Zhang, W.; Franzén, J. Adv. Synth. Catal. 2010, 352, 499. (d) Wu, X.; Liu, Q.; Fang, H.; Chen, J.; Cao, W.; Zhao, G. Chem. Eur. J. 2012, 18, 12196. (e) Huang, Y.-m.; Zheng, C.-w.; Zhao, G.J. Org. Chem. 2015, 80, 3798.

(11) (a) Nahm, S.; Weinreb, S. M. Tetrahedron Lett. 1981, 22, 3815. (b) Balasubramaniam, S.; Aidhen, I. S. Synthesis 2008, 3707.

(12) (a) Hiyamizu, H.; Ooi, H.; Inomoto, Y.; Esumi, T.; Iwabuchi, Y.; Hatakeyama, S. Org. Lett. 2001, 3, 473. (b) Li, W.; Ma, X.; Fan, W.; Tao, X.; Li, X.; Xie, X.; Zhang, Z. Org. Lett. 2011, 13, 3876. (c) Roßbach, J.; Baumeister, J.; Harms, K.; Koert, U. Eur. J. Org. Chem. 2013, 662. (d) Wang, Q.; van Gemmeren, M.; List, B. Angew. Chem. Int. Ed. 2014, 53, 13592.

(13) (a) Chen, Y.; Sieburth, S. M. N. Synthesis 2002, 2191. (b) Kulesza, A.; Ebetino, F. H.; Mazur, A. W. Tetrahedron Lett. 2003, 44, 5511. (c) Matsunaga, S.; Kinoshita, T.; Okada, S.; Harada, S.; Shibasaki, M. J. Am. Chem. Soc. 2004, 126, 7559. (d) Diehl, J.; Brückner, R. Eur. J. Org. Chem. 2017, 278.

(14) Nugent, J.; Schwartz, B. D. Org. Lett. 2016, 18, 3834.

(15) (a) Presset, M.; Coquerel, Y.; Rodriguez, J. J. Org. Chem. 2009, 74, 415. (b) Dudognon, Y.; Presset, M.; Rodriguez, J.; Coquerel, Y.; Bugaut, X.; Constantieux, T. Chem. Commun. 2016, 52, 3010.

(16) The free $\mathrm{N}, \mathrm{O}$-dimethylhydroxylamine was obtained by mixing its commercially available hydrochloride with an equimolar amount of triethylamine in toluene overnight, followed by filtration to remove triethylammonium chloride.

(17) Du, H.; Rodriguez, J.; Bugaut, X.; Constantieux, T. Chem. Eur. J. 2014 $20,8458$.

(18) Alonso, D.; Baeza, A.; Chinchilla, R.; Gómez, C.; Guillena, G.; Pastor, I.; Ramón, D. Molecules 2017, 22, 895.

(19) Okino, T.; Hoashi, Y.; Takemoto, Y. J. Am. Chem. Soc. 2003, 125, 12672.

(20) Okino, T.; Hoashi, Y.; Furukawa, T.; Xu, X.; Takemoto, Y. J. Am. Chem. Soc. 2005, 127, 119.

(21) Hamza, A.; Schubert, G.; Soós, T.; Pápai, I. J. Am. Chem. Soc. 2006, $128,13151$.

(22) (a) Malerich, J. P.; Hagihara, K.; Rawal, V. H. J. Am. Chem. Soc. 2008 , 130, 14416. (b) Jiang, X.; Zhang, Y.; Liu, X.; Zhang, G.; Lai, L.; Wu, L.; Zhang, J.; Wang, R. J. Org. Chem. 2009, 74, 5562. (c) Almași, D.; Alonso, D. A.; Gómez-Bengoa, E.; Nájera, C. J. Org. Chem. 2009, 74, 6163. (d) Manzano, R.; Andrés, J. M.; Pedrosa, R. Synlett 2011, 2203.

(23) Liu, B.; Han, X.; Dong, Z.; Lv, H.; Zhou, H.-B.; Dong, C. Tetrahedron: Asymmetry 2013, 24, 1276.

(24) (a) Vakulya, B.; Varga, S.; Csámpai, A.; Soós, T. Org. Lett. 2005, 7, 1967. (b) McCooey, S. H.; Connon, S. J. Angew. Chem. Int. Ed. 2005 $44,6367$.

(25) Chauhan, P.; Mahajan, S.; Kaya, U.; Hack, D.; Enders, D. Adv. Synth. Catal. 2015, 357, 253

(26) For a previous unsuccessful attempt to react a Weinreb $\beta$ ketoamide with an aliphatic nitroolefin in the presence of a bifunctional thiourea catalyst, see ref $10 \mathrm{a}$.

(27) (a) Taft, R. W. J. Am. Chem. Soc. 1953, 75, 4538. (b) Charton, M. J. Am. Chem. Soc. 1975, 97, 1552. (c) Charton, M. J. Org. Chem. 1976, 41, 2217. (d) Harper, K. C.; Sigman, M. S. J. Org. Chem. 2013, 78, 2813.

(28) (a) Horitsugi, N.; Kojima, K.; Yasui, K.; Sohtome, Y.; Nagasawa, K. Asian J. Org. Chem. 2014, 3, 445. (b) For a related study with other tertiary $\beta$-ketoamides in the presence of a bifunctional supported iminophosphorane-thiourea catalyst, see: Goldys, A. M.; Núñez, M. G.; Dixon, D. J. Org. Lett. 2014, 16, 6294. 
(29) Fujii, H.; Oshima, K.; Utimoto, K. Tetrahedron Lett. 1991, 32, 6147. (30) Evans, D. A.; Chapman, K. T. Tetrahedron Lett. 1986, 27, 5939.

(31) (a) For unsuccessful attempts in the presence of proline, see: Vesely, J.; Rios, R.; Córdova, A. Tetrahedron Lett. 2008, 49, 1137. (b) For a recent highly efficient and selective variant, see: Frias, M.; Mas-Ballesté, R.; Arias, S.; Alvarado, C.; Alemán, J. J. Am. Chem. Soc. 2017, 139, 672 .

(32) For selected reviews, see: (a) Touré, B. B.; Hall, D. G. Chem. Rev. 2009, 109, 4439. (b) Ruijter, E.; Scheffelaar, R.; Orru, R. V. A. Angew. Chem. Int. Ed. 2011, 50, 6234. (c) Climent, M. J.; Corma, A.; Iborra, S. RSC Adv. 2012, 2, 16. (d) Dömling, A.; Wang, W.; Wang, K. Chem. Rev. 2012, 112, 3083. (e) Brauch, S.; van Berkel, S. S.; Westermann, B. Chem. Soc. Rev. 2013, 42, 4948. (f) Cioc, R. C.; Ruijter, E.; Orru, R. V. A. Green Chem. 2014, 16, 2958. (g) Zhu, J.; Wang, Q.; Wang, M.-X., Eds.; Multicomponent Reactions in Organic Synthesis; Wiley-VCH: Weinheim, 2014.

(33) (a) Jiang, B.; Rajale, T.; Wever, W.; Tu, S.-J.; Li, G. Chem. Asian J. 2010, 5, 2318. (b) Bugaut, X.; Bonne, D.; Coquerel, Y.; Rodriguez, J.; Constantieux, T. Curr. Org. Chem. 2013, 17, 1920.

(34) Bugaut, X.; Constantieux, T.; Coquerel, Y.; Rodriguez, J., 1,3Dicarbonyls in Multicomponent Reactions; In Multicomponent Reactions in Organic Synthesis; Zhu, J.; Wang, Q.; Wang, M.-X., Eds; Wiley-VCH: Weinheim, 2014; 109.

(35) (a) Grondal, C.; Jeanty, M.; Enders, D. Nature Chem. 2010, 2, 167. (b) de Graaff, C.; Ruijter, E.; Orru, R. V. A. Chem. Soc. Rev. 2012, 41, 3969. (c) Marson, C. M. Chem. Soc. Rev. 2012, 41, 7712. (d) Volla, C. M. R.; Atodiresei, I.; Rueping, M. Chem. Rev. 2014, 114, 2390.

(36) For selected examples, see: (a) Wu, X.; Dai, X.; Nie, L.; Fang, H.; Chen, J.; Ren, Z.; Cao, W.; Zhao, G. Chem. Commun. 2010, 46, 2733. (b) Rueping, M.; Volla, C. M. R.; Bolte, M.; Raabe, G. Adv. Synth. Catal. 2011, 353, 2853. (c) Du, H.; Rodriguez, J.; Bugaut, X.; Constantieux,
T. Adv. Synth. Catal. 2014, 356, 851. For selected other related strategies for the synthesis of 1,4,5,6,-tetrahydripyridines, see: (d) Rueping, M.; Antonchick, A. P. Angew. Chem. Int. Ed. 2008, 47, 5836 (e) Hong, B.-C.; Liao, W.-K.; Dange, N. S.; Liao, J.-H. Org. Lett. 2013 15, 468. (f) Blümel, M.; Chauhan, P.; Hahn, R.; Raabe, G.; Enders, D. Org. Lett. 2014, 16, 6012. (g) Rong, C.; Pan, H.; Liu, M.; Tian, H.; Shi, Y. Chem. Eur. J. 2016, 22, 2887.

(37) For other organocatalyzed synthetic routes towards 1,2,3,4tetrahydropyridines, see: (a) Han, R.-G.; Wang, Y.; Li, Y.-Y.; Xu, P.-F. Adv. Synth. Catal. 2008, 350, 1474. (b) Veverková, E.; Liptáková, L.; Veverka, M.; Šebesta, R. Tetrahedron: Asymmetry 2013, 24, 548. (c) Tan, Y.; Chen, Y.-J.; Lin, H.; Luan, H.-L.; Sun, X.-W.; Yang, X.-D.; Lin, G.-Q. Chem. Commun. 2014, 50, 15913.

(38) (a) Marigo, M.; Wabnitz, T. C.; Fielenbach, D.; Jørgensen, K. A Angew. Chem. Int. Ed. 2005, 44, 794. (b) Hayashi, Y.; Gotoh, H.; Hayashi, T.; Shoji, M. Angew. Chem. Int. Ed. 2005, 44, 4212. (c) Jensen, K. L.; Dickmeiss, G.; Jiang, H.; Albrecht, Ł.; Jørgensen, K. A. Acc. Chem. Res. 2012, 45, 248. (d) Meninno, S.; Lattanzi, A. Chem. Commun. 2013, 49, 3821.

(39) (a) Dudognon, Y.; Du, H.; Rodriguez, J.; Bugaut, X.; Constantieux, T. Chem. Commun. 2015, 51, 1980. (b) Du, H.; Dudognon, Y.; Sanchez Duque, M. d. M.; Goudedranche, S.; Bonne, D.; Rodriguez, J.; Bugaut, X.; Constantieux, T. Synthesis 2016, 48, 3479.

(40) Relative configuration was attributed thanks to 2D NMR studies and absolute configuration in accordance with literature precedents. See ref. 39 for further details.

(41) Jurberg, I. D.; Peng, B.; Wöstefeld, E.; Wasserloos, M.; Maulide, N. Angew. Chem. Int. Ed. 2012, 51, 1950.

(42) Kouznetsov, V. V. Tetrahedron 2009, 65, 2721.

\section{Biosketches}

\begin{tabular}{|l|l|}
\hline & $\begin{array}{l}\text { Xavier Bugaut studied chemistry the Ecole Nationale Supérieure de Chimie de Montpellier (France) } \\
\text { and carried out his doctoral work on the synthesis of landomycinone under the supervision of Dr. } \\
\text { Emmanuel Roulland, at the Institut de Chimie des Substances Naturelles, Gif-sur-Yvette (France). He } \\
\text { then joined the group of Prof. Frank Glorius at the Westfälische-Wilhems Universität Münster } \\
\text { (Germany) as a postdoctoral fellow, focusing on the development of new NHC-catalyzed } \\
\text { transformations. In October 2011, he was appointed Maître de Conférences (equivalent to assistant } \\
\text { professor) at Aix-Marseille Université (France). Since then, he has worked in collaboration with Prof. } \\
\text { Jean Rodriguez and Prof. Thierry Constantieux, with whom he co-supervised the PhD thesis of Haiying } \\
\text { Du and Yohan Dudognon. His current research interests include enantioselective organocatalysis, with } \\
\text { a focus on its application to multicomponent reactions, to the control of axial chirality and to the } \\
\text { preparation of complex synthetic targets. }\end{array}$ \\
\hline
\end{tabular}

